\title{
Recombinant Viral Capsid Protein L2 (rVL2) of HPV I6 Suppresses Cell Proliferation and Glucose Metabolism via ITGB7/C/EBP $\beta$ Signaling Pathway in Cervical Cancer Cell Lines
}

This article was published in the following Dove Press journal: OncoTargets and Therapy

\author{
Zhihong Chai, ${ }^{1} *$ \\ Yufei Yang, 2,3,* \\ ZhongYi Gu, ${ }^{4, *}$ Xianli Cai, ' \\ Wenwei Ye,' Lin Kong,' \\ Xiaoxiao Qiu,' \\ Lingxiao Ying, \\ Ziliang Wang, 2,3 \\ Linyou Wang' \\ 'Department of Gynecology and \\ Department of Radiology, Taizhou \\ Municipal Hospital Affiliated to Taizhou \\ University School of Medicine, Taizhou \\ 318000, People's Republic of China; \\ ${ }^{2}$ Department of Obstetrics and \\ Gynecology, Xihua Hospital Affiliated to \\ Shanghai Jiaotong University School \\ Medicine, Shanghai 200092, People's \\ Republic of China; ${ }^{3}$ Department of \\ Gynecological Oncology, Fudan \\ University Shanghai Cancer Center, \\ Shanghai 200032, People's Republic of \\ China; 'Department of Nephrology, \\ Children's Hospital of Fudan University, \\ Shanghai 201 I02, People's Republic of \\ China \\ *These authors contributed equally to \\ this work
}

Correspondence: Ziliang Wang Department of Obstetrics and Gynecology, Xihua Hospital Affiliated to Shanghai Jiaotong University School Medicine, 1665 Kongjiang Road, Shanghai 200092, People's Republic of China Email huf_zlwang@|26.com

Linyou Wang

Department of Radiology, Taizhou Municipal Hospital, 38I East Zhongshan Road, Taizhou 318000, People's Republic of China

Email wanglinyou2007@I63.com

\begin{abstract}
Purpose: Capsid protein L2 is the minor capsid protein of human papillomavirus 16 (HPV16). Although L2-based vaccines were developed, the therapeutic effect of recombinant viral capsid protein L2 (rVL2) was still to be illustrated.

Methods: We used glucose uptake and lactate production assay to verify the inhibitory effect of rVL2 on the glucose metabolism in cervical cancer cells. Secondly, we performed gene-chip assay, RT-PCR, and Western blot to determine the role of ITGB7/C/EBP $\beta$ signaling pathway in rVL2-mediated glucose metabolism in vitro. Finally, we used an animal model to verify the function of rVL2 in cervical cancer.
\end{abstract}

Results: We found that rVL2 reduced glucose uptake and lactate production levels in cervical cancer cells, which caused the inhibition of cell proliferation. rVL2 decreased the expression levels of key metabolic enzymes, including GLUT1, LDHA, and ALDOA, to affect cell metabolism in cervical cancer cells by inhibiting ITGB7/C/EBP $\beta$ signaling pathway in vitro and in vivo.

Conclusion: These results demonstrated the vital role of rVL2 in the glycolysis-induced cell growth and proliferation via suppressing ITGB7/C/EBP $\beta$ signaling axis.

Keywords: recombinant viral capsid protein L2, rVL2, C/EBP $\beta$, glucose metabolism, cervical cancer

\section{Introduction}

Human papillomavirus (HPV)-induced cervical cancer is one of the most frequent cancers in women of underdeveloped countries. ${ }^{1}$ Nearly about one-third of the patients with cervical cancer experience recurrence, ${ }^{2}$ and recurrence mostly occurs within 2 years of therapy completion. ${ }^{3}$ Hence, new therapeutic targets and treatment strategies remain needed.

HPV 16 is a kind of papillomavirus involved in approximately $60 \%$ of all cervical cancers worldwide. ${ }^{4} \mathrm{HPV}$ is an enormous family, which is composed of the non-enveloped dsDNA virues. ${ }^{5}$ Papillomaviruses have an $8 \mathrm{Kd}$ DNA genome, which contained 360 copies of the major capsid protein L1(VL1) and 12-36 copies of the minor capsid protein L2(VL2). ${ }^{6,7} \mathrm{VL} 1$ forms pentamers that take for the majority of the capsid surface, while VL2 is mainly buried in the capsid, exposing the N-terminal residues on the surface. ${ }^{8}$ VL2 protects the viral genome and 
promotes the cell attachment, internalization, and transport of the viral genome to the host cell nucleus to initiate viral replication. ${ }^{9}$ Previous studies have shown that VL2 had impact on several different cellular factors, including cellular proteins, nucleic acids, and membranes in different cellular compartments. ${ }^{10-14}$ Although VL2-based vaccines have been developed, the therapeutic effect of recombinant viral capsid protein L2 (rVL2) still remains illustrated.

Enhanced glucose uptake and aerobic glycolysis was one of the fundamental phenotypes of malignant tumors ${ }^{15}$ and was important for tumor relapse and chemoresistance. ${ }^{16}$ In the previous study, it has been reported that integrin $\beta 4$ (ITGB4) could promote lymph node metastasis and glucose metabolism of cervical cancer by activating the SNAI1/SIRT3 signaling pathway. ${ }^{17}$ In this study, we also found that rVL2 inactivated the integrin $\beta 7$ (ITGB7)/FAK signaling pathway to suppress the proliferation of cervical cancer cells. ITGB7 was expressed primarily by leukocytes ${ }^{18}$ and participated in various cell functions. ${ }^{19}$ ITGB7 has been reported to participate in the pathogenesis of several kinds of lymphoid malignancies, such as lymphomatous polyposis in mantle cell lymphoma, ${ }^{20}$ thymic lymphoma, ${ }^{21}$ and mucosa-associated T- and B-cell non-Hodgkin lymphomas. ${ }^{22}$ However, its regulatory functions in cervical cancer remain investigated.

CCAAT/enhancer binding protein-beta $(\mathrm{C} / \mathrm{EBP} \beta)$ is one member of the C/EBPs family and affected key biological processes including cell proliferation and tumor invasiveness. ${ }^{23}$ In previous studies, $\mathrm{C} / \mathrm{EBP} \beta$ was found to induce metastatic gene expression in prostate cancer cells. $^{24}$ Meanwhile, C/EBP $\beta$ was also found to be a potential target for colorectal cancer treatment via suppression of miR-223. ${ }^{25}$ However, the role of $\mathrm{C} / \mathrm{EBP} \beta$ in cell metabolism remains illustrated.

In this study, we detected the inhibitory effect of rVL2 on glucose uptake and lactate production in cervical cancer cells. We demonstrated that rVL2 suppressed glucose metabolism in cervical cancer cells via inhibiting ITGB7/ $\mathrm{C} / \mathrm{EBP} \beta$ signaling axis.

\section{Materials and Methods}

\section{Cell Lines and Cell Culture}

Siha and Caksi are human cervical cancer cell lines, which were purchased from the Cell Bank of the Chinese Academy of Science. Siha and Caksi cells were cultured in Dulbecco's modified Eagle's medium (DMEM, HyClone, Thermo Scientific, Waltham, MA) and 10\% fetal bovine serum (Gibco, Life Technologies, Carlsbad, CA), 100 U/mL penicillin (Biowest, Nuaillé, France), and $100 \mathrm{U} / \mathrm{mL}$ streptomycin (Biowest, Nuaillé, France) were supplemented. These cells were incubated at $37^{\circ} \mathrm{C}$ in a humidified atmosphere with $5 \% \mathrm{CO}_{2}$.

\section{Purification of Recombinant L2 Protein}

HPV16 capsid protein L2 is localized to punctate nuclear regions identified as promonocytic leukemia protein oncogenic domains (PODs). Recombinant viral capsid protein L2 was manufactured as peptide synthetically and purchased from Yunmai Company (Shanghai, China), with a concentration of $5 \mu \mathrm{g} / \mathrm{uL}$. The recombinant viral capsid protein L2 is diluted with PBS at a proportion of $1: 1$.

\section{Plasmid Construction and Cell \\ Transfection}

$\mathrm{pLKO} / \mathrm{shC} / \mathrm{EBP} \beta-1$ or 2 was constructed according to the previously reported method. ${ }^{26}$ The control vector was similarly constructed by directly inserting oligonucleotides encoding short hairpin RNA against green fluorescence protein mRNA (shGFP) into the pLKO.1 vector. The cDNA sequences of ITGB7 was sub-cloned into pcDNA3.1 (-) expression vector (Invitrogen, Carlsbad, CA, USA) to construct recombinant plasmids pcDNA3.1 (-)-ITGB7, which was transfected into Siha and Caski cells according to the manufacturer's instructions. ${ }^{26}$

\section{RNA-seq Data Analysis}

RNA-seq was performed as described previously. ${ }^{26}$ Gene Set Enrichment Analysis (GSEA) was used for gene functional annotation.

\section{Glycolysis Analysis}

Glycolysis analysis was performed as previously described. ${ }^{27}$

\section{Immunohistochemistry Assay}

The tissue microarray (TMA) was obtained from FUSCC Tissue Bank. Searches involving human participants in this study were approved by the Ethics Committee of FUSCC. Written informed consent was also approved and obtained from each participant, and each clinical investigation was conducted according to the principles expressed in the Declaration of Helsinki consent. IHC was performed on $7-\mu \mathrm{m}$-thick TMA sections using the antibody against ITGB7 (ab95816, rabbit polyclonal antibody, Abcam, 1:100 dilution), p-FAK (Tyr 925) (ab38512, rabbit polyclonal antibody, Abcam, 1:100 dilution), 
p-AKT1 (Ser 473) (ab81283, rabbit polyclonal antibody, Abcam, 1:100 dilution), and $\mathrm{p}-\mathrm{C} / \mathrm{EBP} \beta$ (\#3084, rabbit polyclonal antibody, Cell Signal Technology, 1:100 dilution). Each case contained two cores made from separate sources to preclude the heterogeneity of tumors. A known positive case sample was regarded as a positive control, and the primary antibody used non-immune mouse/rabbit serum for negative control. The immunoreactive score (IRS) was multiplicity of the staining intensity and positive cancer percentage. Finally, the assessment of the protein expression was defined as negative $(\leq 1+)$ and positive $(>2+$ to $\leq 3+)$.

\section{Cell Viability and Colony Formation Assay}

Cell line sensitivity to the indicated treatment was determined through Cell Viability Assay described previously. ${ }^{26}$

\section{Western Blot Analysis}

The expression levels of various proteins in Siha and Caski cells were determined by Western blot analysis as previously described. ${ }^{26}$ Antibodies to GLUT1(21829-1-AP), LDHA (19987-1-AP), and ALDOA (11217-1-AP) were acquired from Proteintech TM. Antibodies to ITGB7, FAK, p-FAK (Tyr 925), AKT1, p-AKT1 (Ser 473), C/EBP $\beta$, and p-C/ $\operatorname{EBP} \beta$ (Thr 235) were from Abcam. The antibody to $\beta$-actin (A5441) was obtained from Sigma-Aldrich.

\section{In vivo Tumor Growth Assay}

Animal experiments were permitted by the Ethics Committee at FUSCC and performed as previously described. ${ }^{26}$ All animal experiments were approved by the Institutional Animal Care and Use Committee of Fudan University and performed according to institutional guidelines. When an average tumor volume reached $100 \mathrm{~mm}^{3}$, mice were randomized into groups $(n=5)$. Then, they were intraperitoneally treated with $\mathrm{rVL} 2(10 \mathrm{mg} / \mathrm{kg})$ or PBS as the control thereafter. Administration of vehicle or agents and measurement of tumor growth with a digital caliper were performed once every other day. After treated with or without $\mathrm{rVL} 2$, all the mice were subjected to perform positron emission tomography/computed tomography (PET/CT) scan and were evaluated by the standard uptake value (SUV). At last, the xenograft tumors were dissected and weighed 1 week after the last rVL2 injection. The expression levels of the genes in xenograft tumor were detected by qRT-PCR assay.

\section{Statistical Analysis}

SPSS software (version 18.0) was used for statistical analysis. Comparing quantitative data used with Student's $t$-test or ANOVA analysis. $\mathrm{P}<0.05$ (two-tailed) was regarded as statistically significant.

\section{Results}

\section{rVL2 Inhibits Cell Proliferation and Glycolysis in Cervical Cancer Cell Lines}

Siha and Caski cells were treated with different concentrations of rVL2 for 24 hours (Figure 1A). In each cell lines, rVL2 treatment significantly reduced cell viability in a dose-dependent manner $(\mathrm{P}<0.05$, Figure $1 \mathrm{~A})$. The half-maximal inhibitory concentration (IC50) values of rVL2 on Siha and Caski cells were $0.065 \mu \mathrm{M}$ and 0.081 $\mu \mathrm{M}$, respectively.

By the gene-chip analysis, we found that the genes related to oxidative phosphorylation and glycolysis were enriched in cells treated with rVL2 (Figure 1B) and were suppressed by rVL2 treatment (Figure 1C and D), which were confirmed by the results of qRTPCR assay shown in Figure 1E and F. Subsequently, we used glucose uptake and lactate production assays to explore the impact of rVL2 on cell glycolysis in cervical cell lines. We found that rVL2 effectively reduced the levels of glucose uptake and lactate production in Siha and Caski cells, which were consistent with the results of colony formation assays (Figure 2G and $\mathrm{H}$ ). The results of Western blotting assay showed that the expression levels of GLUT1, LDHA, ALDOA were downregulated by rVL2 (Figure 2I).

\section{rVL2 Inhibits Glucose Metabolism by Inducing the Expression of ITGB7/FAK/ AKTI Signaling Pathway}

We further found that the genes participated in the integrin pathway were enriched in cells treated with rVL2 (Figure 3A), and the results of Western blotting indicated that rVL2 decreased the expression levels of ITGB7, FAK, p-FAK (Tyr 925), AKT1, p-AKT1 (Ser 473), $\mathrm{C} / \mathrm{EBP} \beta$, and $\mathrm{p}-\mathrm{C} / \mathrm{EBP} \beta$ (Thr 235) in Siha and Caski cells (Figure 3B). To confirm the role of ITGB7 in rVL2- induced glycolysis inhibition, we introduced ITGB7 cDNA into Siha and Caski and treated with rVL2 $(50 \mu \mathrm{M})$. As shown in Figure $3 \mathrm{C}-\mathrm{F}$, the overexpression of ITGB7 rescued the function of rVL2 on 
A

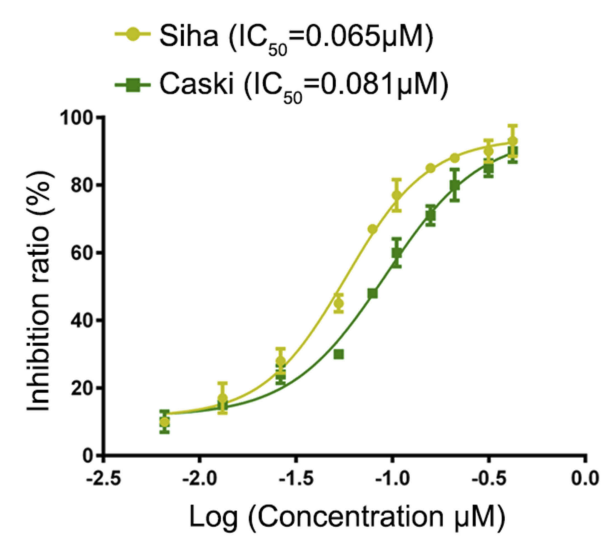

C

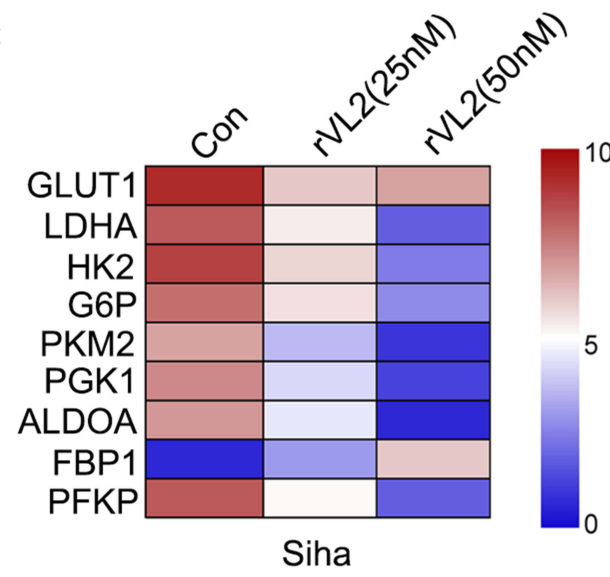

D

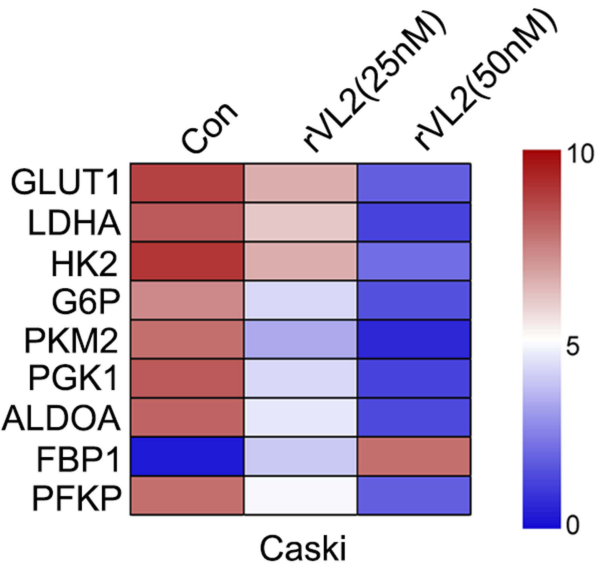

B

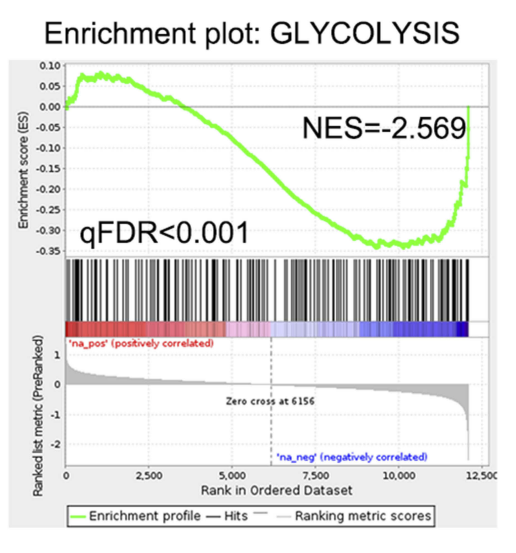

Enrichment plot:
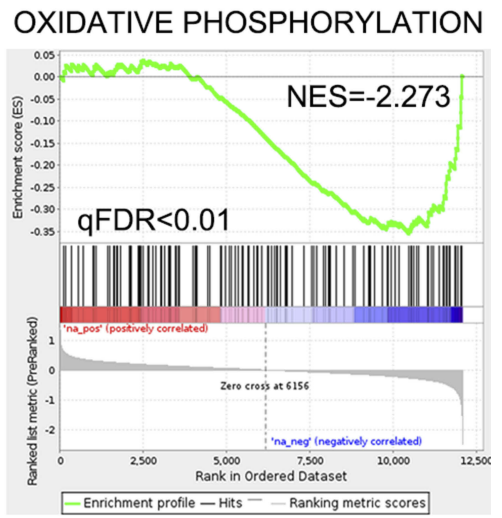

Siha

E

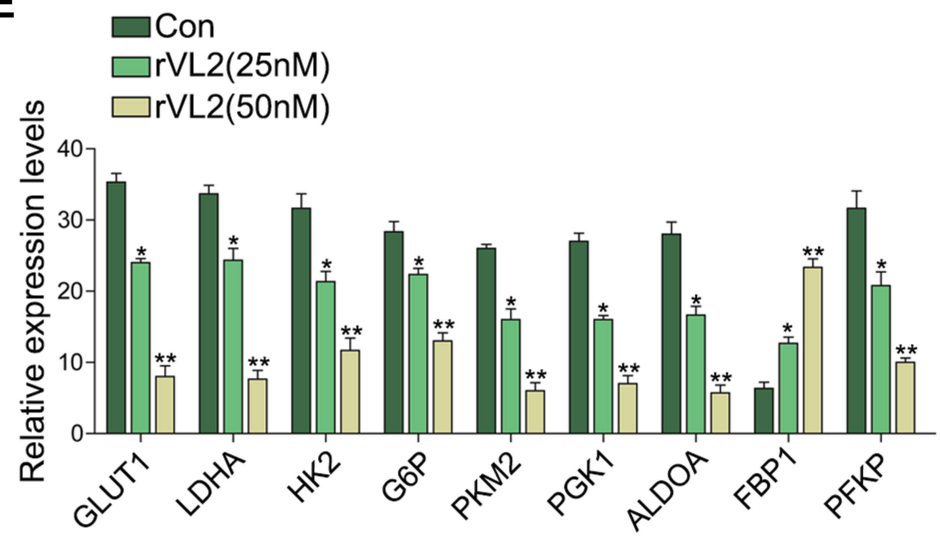

F

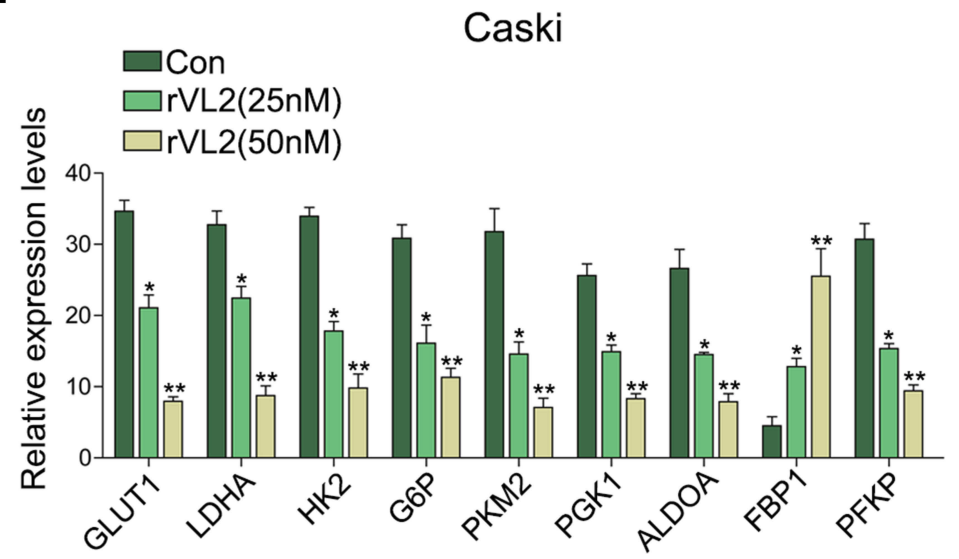

Figure I Recombinant viral capsid protein L2 (rVL2) suppresses cell proliferation by inhibiting cell glycolysis. (A) rVL2 inhibited in cell viability in a dose-dependent manner in Siha and Caski cells detected by CCK-8 kit. (B-D) Analysis of cell function regulated by gene-chip assay. (E and F) rVL2 decreased the mRNA levels of GLUTI, LDHA, HK2, G6P, PKM2, PGKI, ALDOA, and PFKP detected by qRT-PCR in Siha and Caski cells treated by rVL2 (*P $<0.05, * * P<0.01)$.

glucose uptake, lactate production, ATP production, and NADPH production levels in both cell lines. The expression levels of ITGB7, p-FAK (Tyr 925), p-AKT1 (Ser 473), and $\mathrm{p}-\mathrm{C} / \mathrm{EBP} \beta$ (Thr 235) were rescued by the introduction of ITGB7 cDNA in Siha and Caski cells treated by rVL2 (Figure 3G). Taken together, rVL2 might regulate the glucose metabolism through ITGB7/FAK/AKT1/C/EBP $\beta$ signaling pathway. 


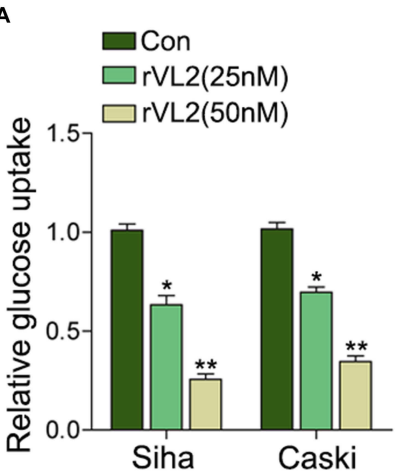

C

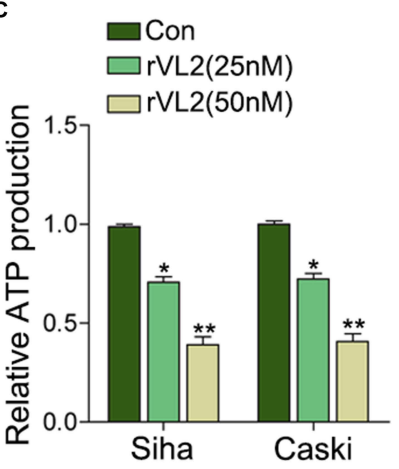

F

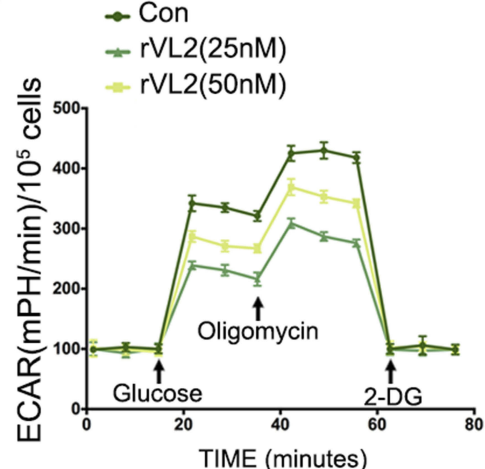

G

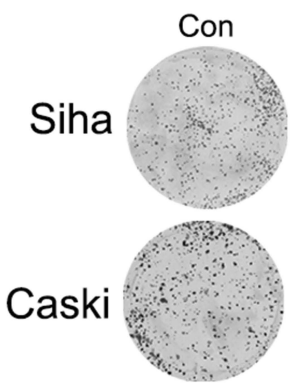

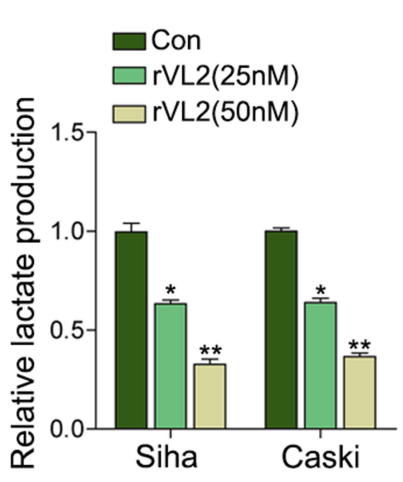

D

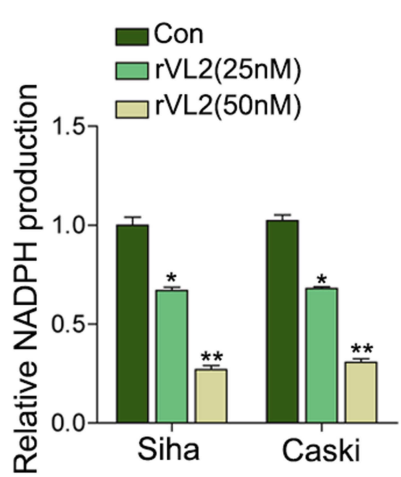

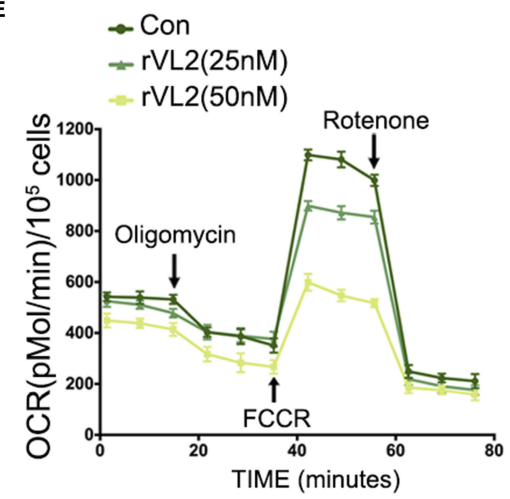
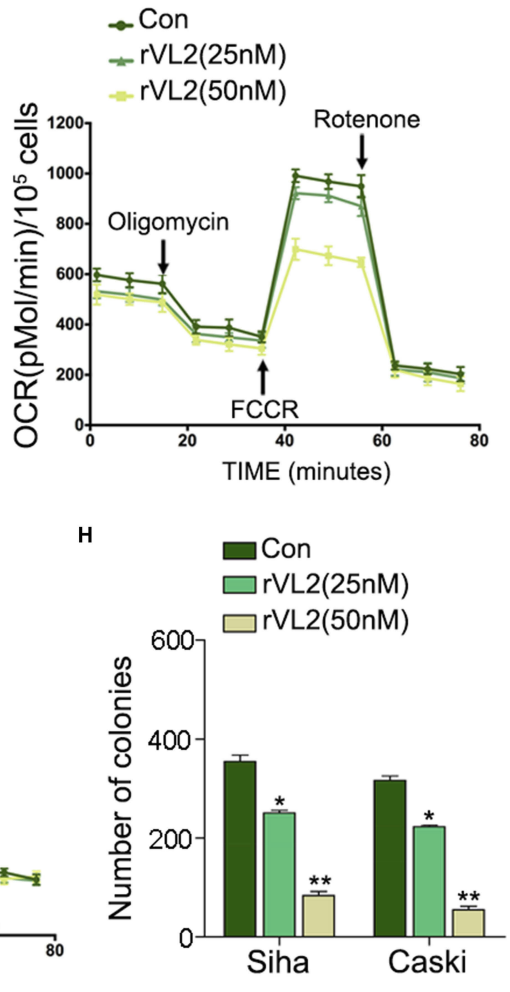
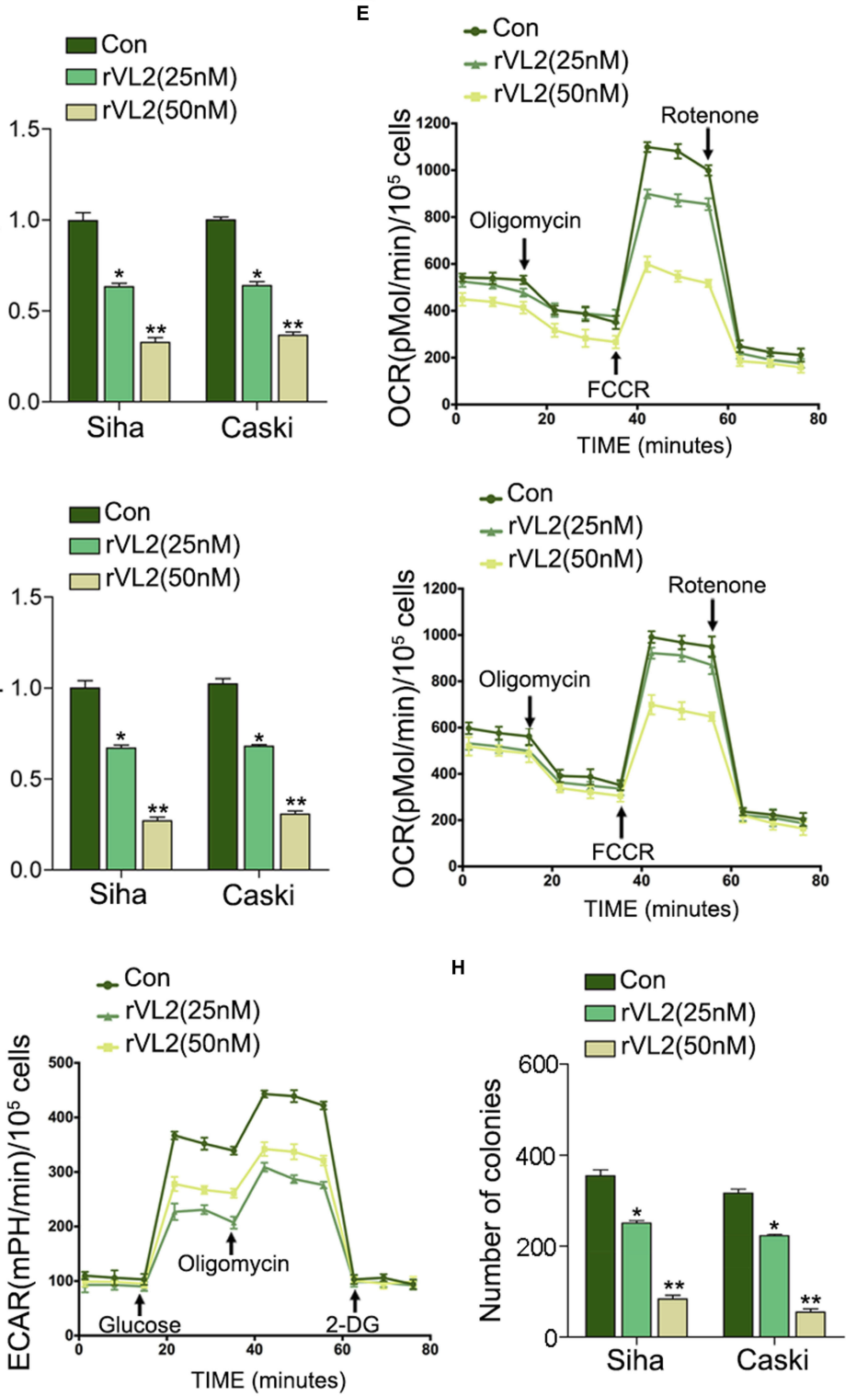


\section{rVL2 Inhibits the Promoter Activity of GLUTI, LDHA, and ALDOA by Suppressing the ITGB7/C/EBP $\beta$ Signaling Pathway in Cervical Cancer Cells}

As $\mathrm{C} / \mathrm{EBP} \beta$ was an important transcriptional factor in tumorigenesis, we inferred that $\mathrm{C} / \mathrm{EBP} \beta$ might regulate the promoter activity of the genes involved in the glucose metabolism. To verify our hypothesis, we knocked down the expression level of C/EBP $\beta$ in Siha/ITGB7 OE and Caski/ITGB7 OE cell lines. Silencing of $\mathrm{C} / \mathrm{EBP} \beta$ decreased mRNA expression level (Figure 4A) and promoter activity (Figure 4B) of GLUT1, LDHA, and ALDOA in Siha/ITGB7 OE and Caski/ITGB7 OE cell lines treated by rVL2, compared with their controls. Furthermore, we found that the knockdown of $\mathrm{C} / \mathrm{EBP} \beta$ directly reduced the mRNA expression levels (Figure 4C) and promoter activity (Figure 4D) of GLUT1, LDHA, and ALDOA in Siha cells.

\section{rVL2 Regulates Cell Proliferation and Glycolysis of Cervical Cancer Cells in vivo}

We further established subcutaneous tumor formation by injecting Siha cells into nude mice. We found that rVL2 obviously retarded the growth of xenograft tumor, compared to control group (Figure 5A-C). We also found that rVL2 effectively decreased the glucose uptake levels in xenograft tumors (Figure 5D). The results of immunohistochemical staining performed that the expression levels of ITGB7, p-FAK (Tyr 925), p-AKT1 (Ser 473), and p-C/EBP $\beta$ (Thr 235 ) in xenograft models were decreased (Figure 5E). Furthermore, we found the expression of GLUT1, LDHA, HK2, G6P, PKM2, PGK1, ALDOA, and PFKP were reduced in xenograft tumors treated by rVL2, while the expression level of FBP1 was enhanced (Figure 5F).

\section{Discussion}

In this study, we demonstrated that rVL2 decreased glucose metabolism via ITGB7/C/EBP $\beta$ signaling pathway to inhibit cervical cancer cell proliferation, which supplied the new evidence on the treatment of cervical cancer. The growing studies have determined the vital role of rVP1in the tumorigenesis in various cancers. For example, rVP1 was found to suppress the progression of hepatocellular carcinoma $^{28,29}$ and cell metastasis of ovarian cancer cells. $^{30}$ Nowadays, the virus-like particles (VLPs) based on L2 proteins have been regarded as a potential candidate for vaccine development against HPV infections. ${ }^{31}$ In the present study, we demonstrated that rVL2 had the anticancer effects on cervical cancer cells in a dose-dependent manner and further found that rVL2 reduced cell glycolysis level in cervical cancer cells by inhibiting ITGB7/C/ EBP $\beta$ signaling pathway, which exploded the new insight of rVL2 in the cancer treatment.

Integrins are principal cell surface receptors responsible for cell extracellular matrix interactions, which are formed by associations of $\alpha$ and $\beta$ dimers. Integrins are involved in a variety of biological processes associated with cancer development, such as migration, invasion, differentiation, proliferation, and survival. Taken example, integrin $\beta 4$ (ITGB4) was detected as a novel prognostic factor in colon cancer, ${ }^{32}$ integrin $\beta 1$ (ITGB1) functioned on the cell stemness in head and neck squamous cell carcinoma (HNSCC), ${ }^{33}$ and integrin alpha 7 (ITGA7) promoted cell proliferation and was related to poor prognosis and survival profiles in non-small-cell lung cancer (NSCLC). ${ }^{34}$ Our results identified that rVL2 exerted its anti-cancer effects through the suppression of ITGB7-induced signaling pathway, which further confirmed the key role of integrins in the tumorigenesis in various cancers.

$\mathrm{C} / \mathrm{EBP} \beta$ is a kind of transcription factor regulating critical biological processes including cellular growth and tumor invasiveness. ${ }^{24} \mathrm{C} / \mathrm{EBP} \beta$ upregulation promoted tumor cell invasion in an MMP3-dependent manner and was associated with metastasis in esophageal squamous cell carcinoma (ESCC). ${ }^{35}$ Compared with previous studies, our results revealed the new evidence that $\mathrm{C} / \mathrm{EBP} \beta$ may be a downstream target for ITGB7, which further affected the expression of proteins linked to glycolysis, such as GLUT1, LDHA, and ALDOA, which further determined that the regulatory function of rVL2 on cell proliferation by suppressing glycolysis in cervical cancer. Therefore, our results provided new data to clarify the therapeutic mechanism of rVL2 in cancer cells.

Despite the significant developments in detection and therapy of cervical cancer during the past decades, cervical cancer still remains a high rate of mortality due to the drug resistance. ${ }^{2}$ In the past years, chemoresistance and tumor relapse have been found to be related to the enhanced glucose uptake and aerobic glycolysis. ${ }^{16}$ For instance, glucose transporter 1 (GLUT1) has been determined to promote the malignant phenotype of non-small cell lung cancer through Integrin $\beta 1 / \mathrm{Src} / \mathrm{FAK}$ Signaling pathway. ${ }^{36}$ In the present study, the expression levels of GLUT1, LDHA, and ALDOA were decreased by the treatment of 
A

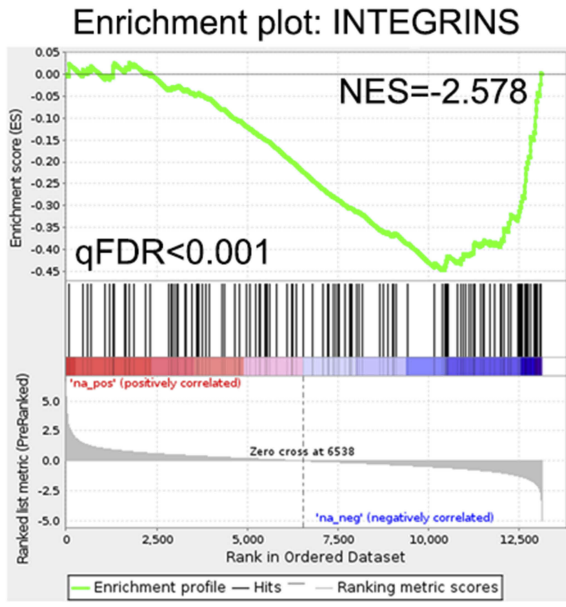

B

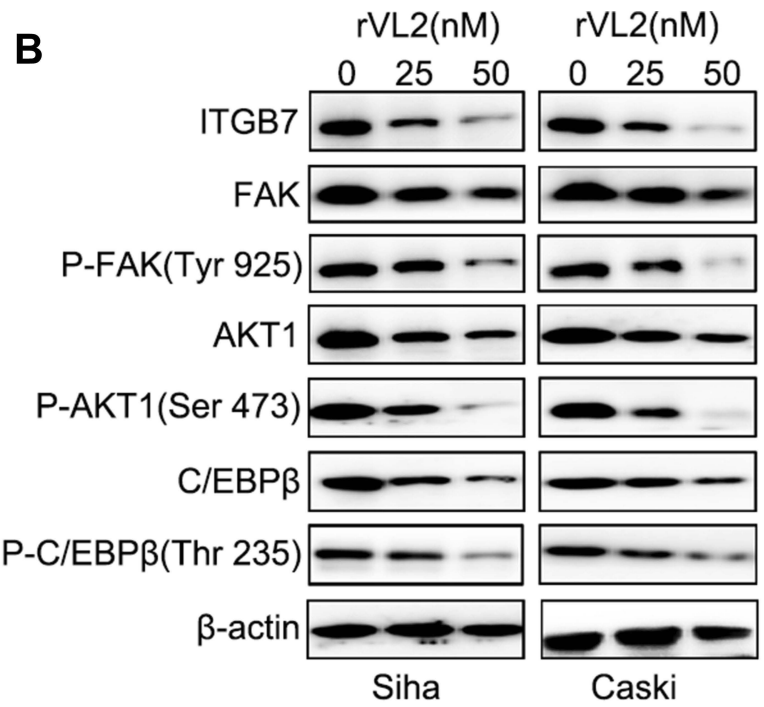

C

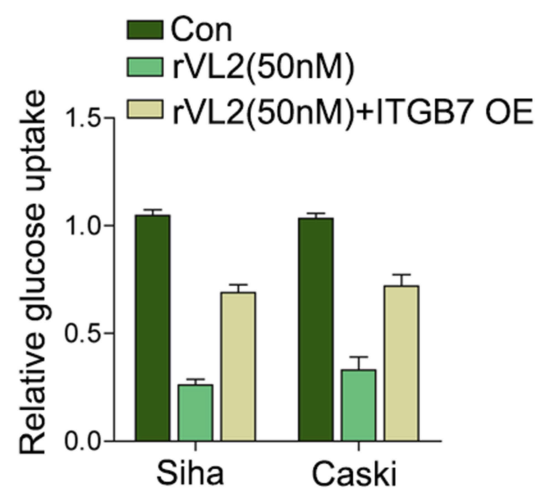

D

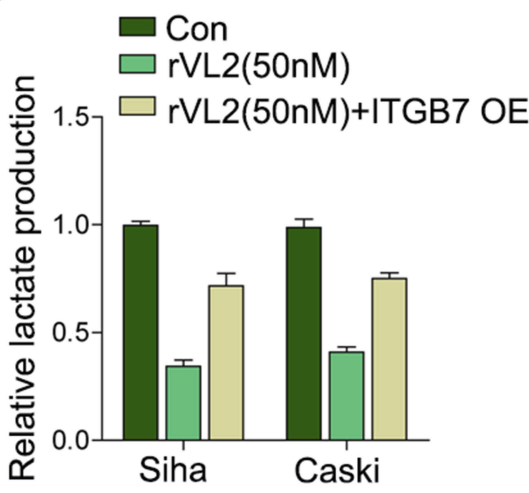

E

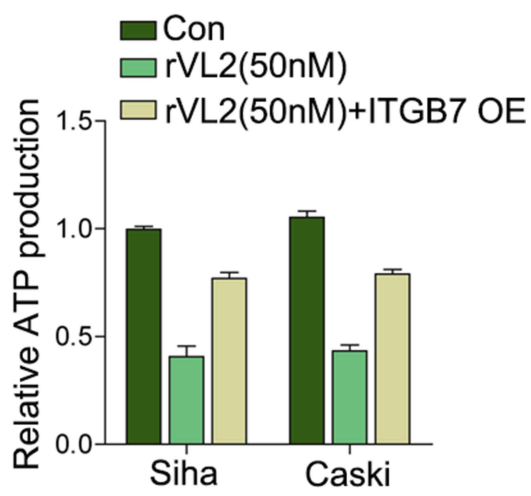

F

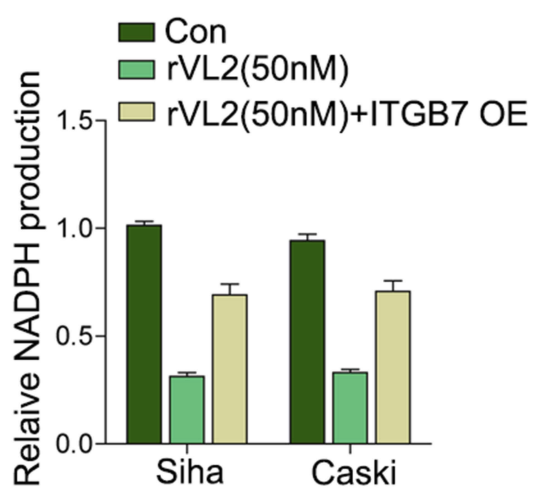

G

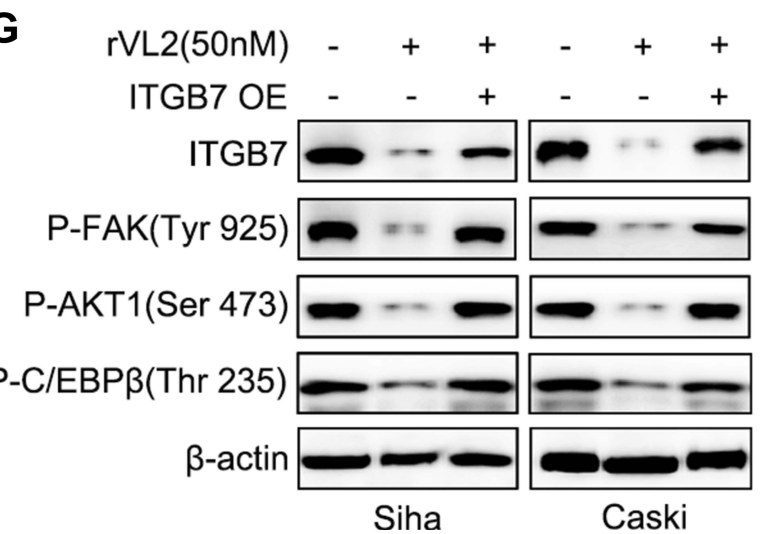

Figure $3 \mathrm{rVL} 2$ regulates glucose metabolism by suppressing ITGB7/C/EBP $\beta$ signaling pathway. (A) Analysis of cell function regulated by gene-chip assay. (B) The results of Western blot exhibited that ITGB7, p-FAK, AKTI, p-AKTI, C/EBP, and p-C/EBP及 protein expression levels were downregulated by treatment of $r$ VL2. (C-G) ITGB7 overexpression rescued the induction of rVL2 on the glucose uptake, lactate production, ATP production, and NADPH production detected by real-time PCR and Western blot.

rVL2. rVL2 could inhibit the transcription of GLUT1, LDHA, and ALDOA by suppressing the ITGB7/C/EBP $\beta$ signaling pathway in cervical cancer cells. These findings revealed the new effect of rVL2 on cell proliferation and drug resistance in cancer cells.
In sum, we identified a vital role for rVL2 in glucose metabolism and cell proliferation. Our data also provided the new mechanistic insight into the effect of $\mathrm{rVL} 2 / \mathrm{ITGB} 7 / \mathrm{C} /$ EBP $\beta$ signaling axis in the progression of cervical cancer cells. Therefore, rVL2 may warrant consideration as 

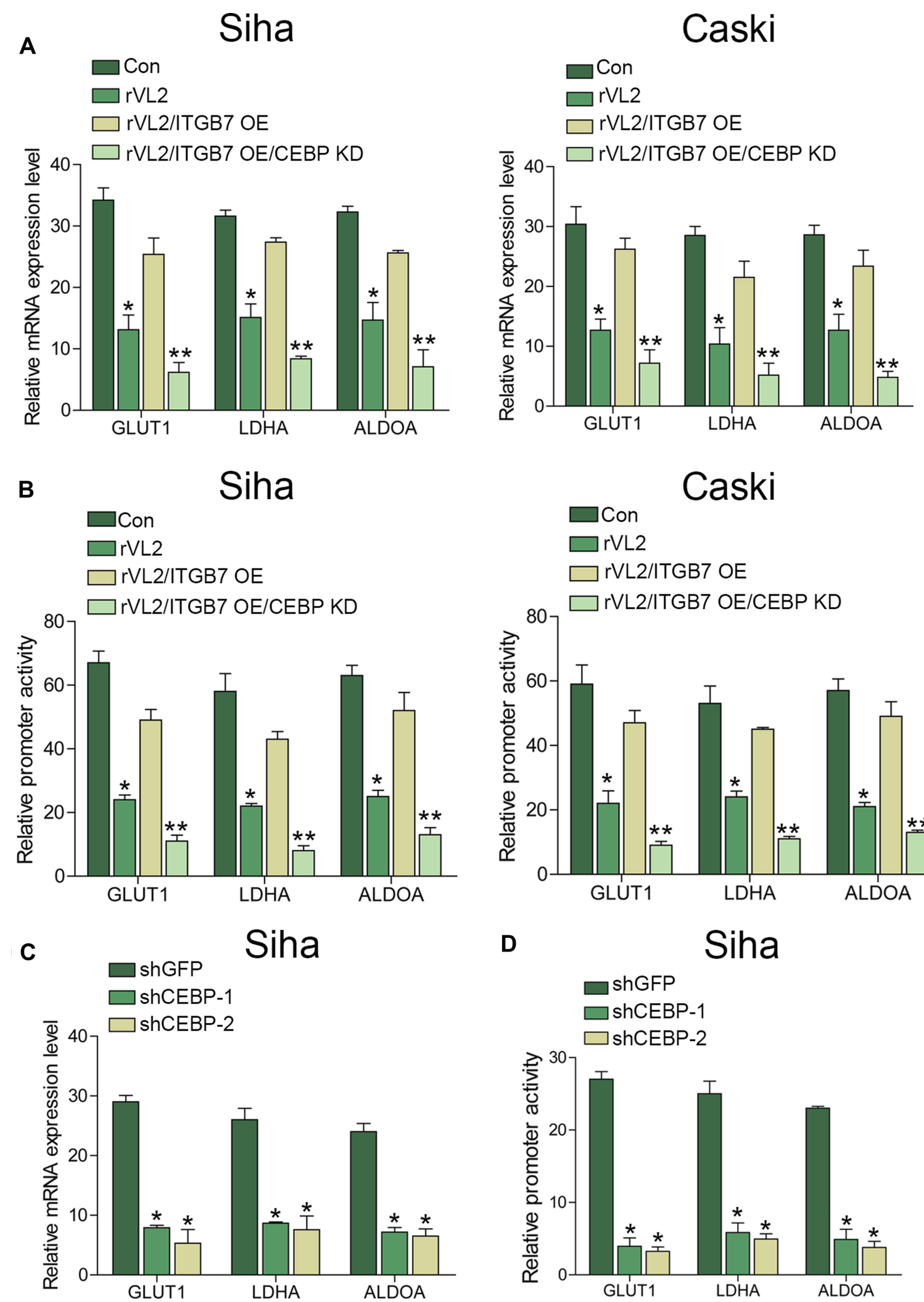

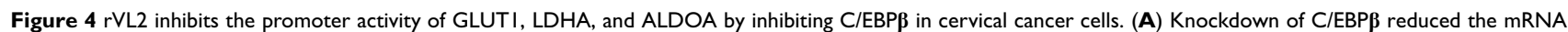
expression levels in Siha/ITGB7 OE and Caski/ITGB7 OE cells treated with $r V L 2$. ( ${ }^{* P}<0.05$, $\left.{ }^{* * P}<0.01\right)$. (B) Knockdown of C/EBPB reduced the promoter activity in Siha/ ITGB7 OE and Caski/ITGB7 OE cells treated with rVL2. (*P< 0.05, **P $<0.01)$. (C and D) Silencing effect of C/EBP $\beta$ with shRNAs was detected by real-time PCR. $* P<0.05$. 


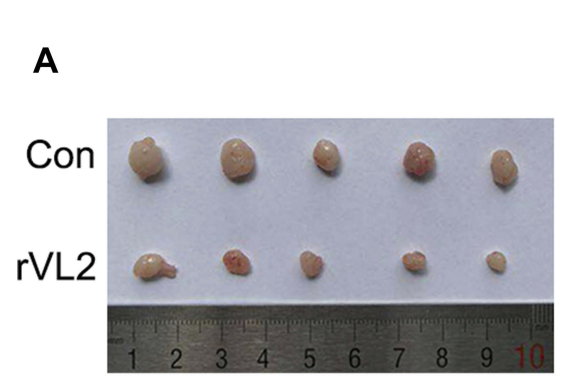

D
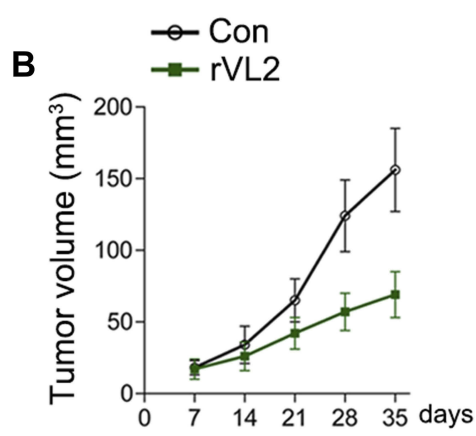

rVL2

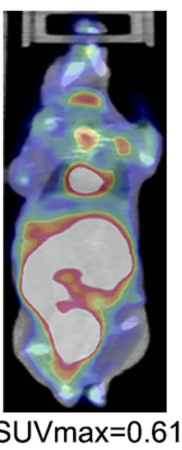

C

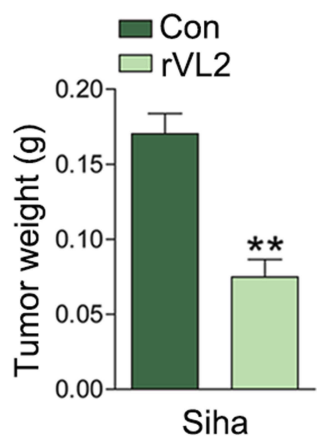

$\mathbf{E}$
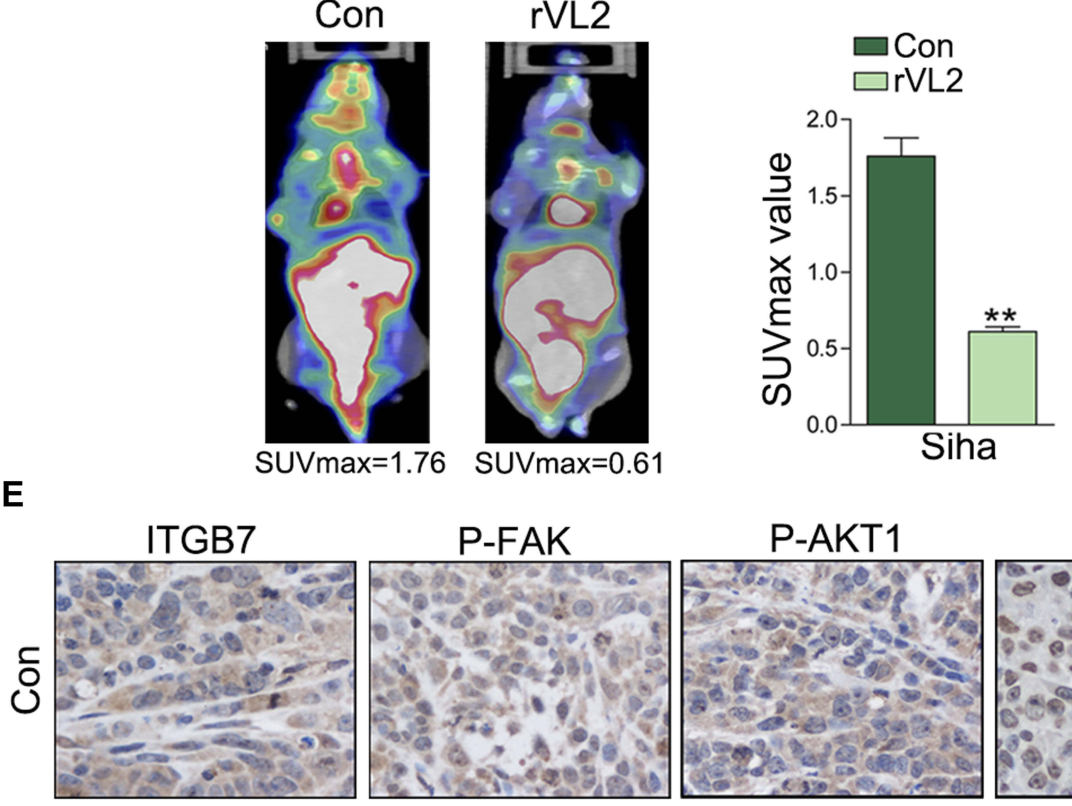

P-FAK
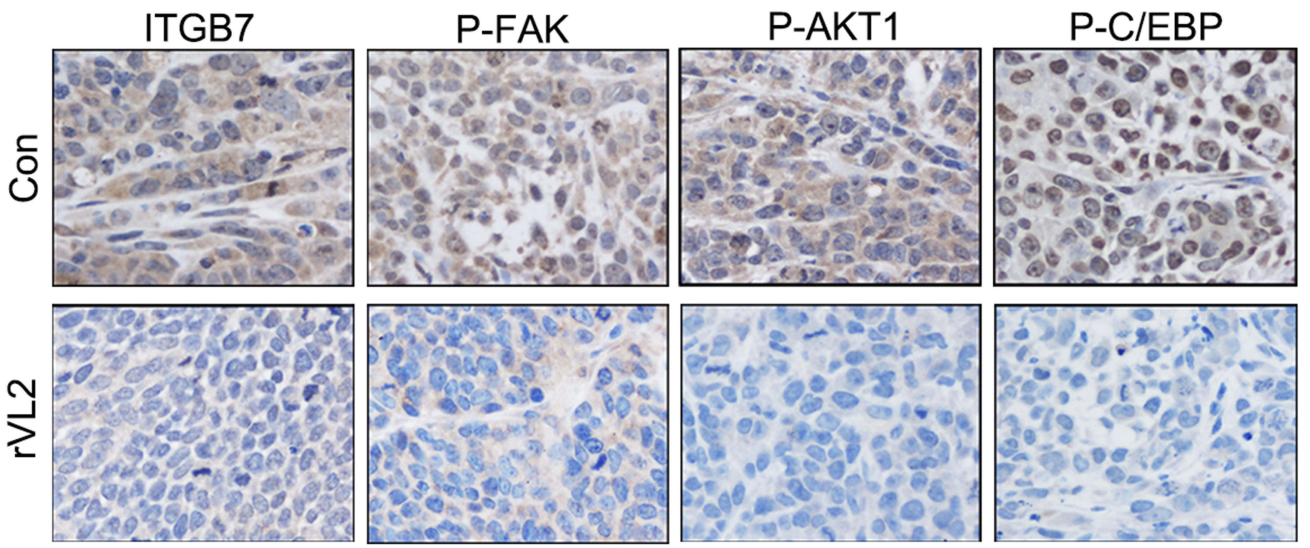

F

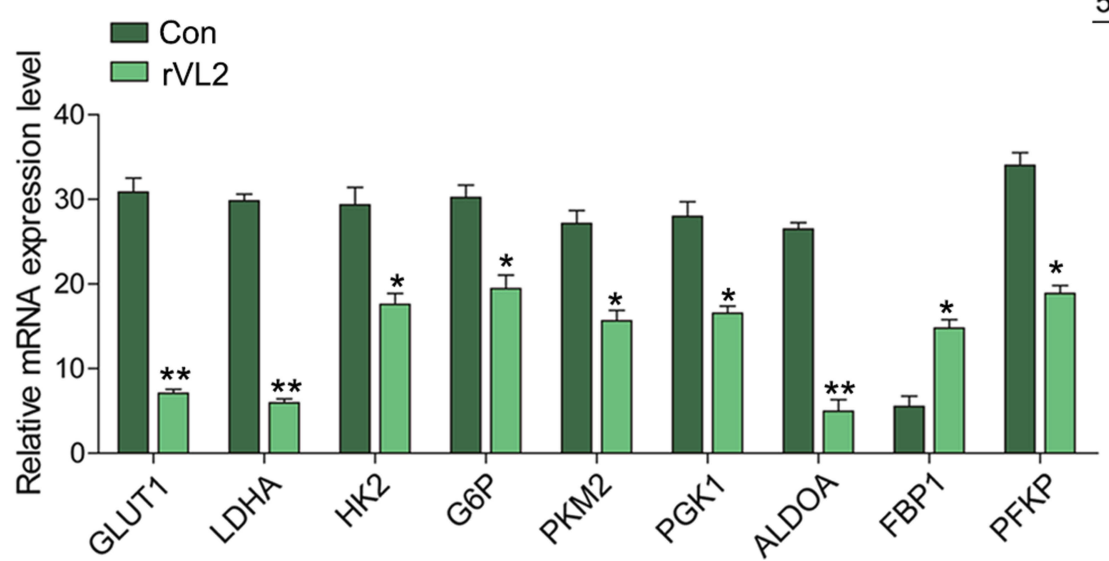

$\underline{50 \mu \mathrm{m}}$

Figure 5 rVL2 inhibits cell proliferation and glycolysis of cervical cancer cells in vivo. (A) Treatment with rVL2 slowed the speed of tumor growth in vivo $(P<0.05)$. (B and $\mathbf{C})$ The tumor volume and weight in the experimental group were significantly lower than those in control group (**P $<0.01)$. (D) $r V L 2$ can significantly suppress the glucose uptake in cervical cancer in vivo and resulted in a lower SUVmax value (**P< $<0.01)$. (E) Immunohistochemical analyses of ITGB7, p-FAK, p-AKTI, and p-C/EBP $\beta$ expression in tissues. (F) The expression levels of GLUTI, LDHA, HK2, G6P, PKM2, PGKI ALDOA, FBPI, and PFKP were detected by real-time PCR in xenograft tumors and the corresponding controls (*P $<0.05$, **P< 0.01 ). 
a predictive agent for the therapy of cervical cancer patients in prospective clinical studies.

\section{Abbreviations}

rVL2, recombinant viral capsid protein L2; C/EBP $\beta$, CCAAT/ enhancer-binding protein $\beta$; ITGB2, integrin $\beta 2$; GLUT1, glucose transporter protein-1; LDHA, lactate dehydrogenase A; HK2, hexokinase 2; G6P, glucose-6-phosphatase; PKM2, pyruvate kinase isozymes M2; PGK1, phosphoglycerate kinase 1; ALDOA, aldolase A, fructose-bisphosphate; PFKP, platelet phosphofructokinase.

\section{Acknowledgements}

This work was funded by National Nature Science Foundation of China (81872117) for Ziliang Wang and General Social Development Projects of Taizhou Science and Technology Bureau (1801KY56) for Zhihong Chai.

\section{Disclosure}

The authors report no conflicts of interest in this work.

\section{References}

1. Sniadecki M, Swierzko A, Dabkowski M, et al. New therapeutic approaches in the treatment of node-positive cervical cancer patients based on molecular targets: a systematic review. Ginekol Pol. 2019;90(6):336-345. doi:10.5603/GP.2019.0062

2. Chatterjee K, Mukherjee S, Vanmanen J, Banerjee P, Fata JE. Dietary polyphenols, resveratrol and pterostilbene exhibit antitumor activity on an HPV E6-positive cervical cancer model: an in vitro and in vivo analysis. Front Oncol. 2019;9:352. doi:10.3389/fonc.2019.00352

3. Hong CM, Park SH, Chong GO, et al. Enhancing prognosis prediction using pre-treatment nodal SUVmax and HPV status in cervical squamous cell carcinoma. Cancer Imaging. 2019;19(1):43. doi:10.1186/s40644-019-0226-4

4. Guan Y, Castle PE, Wang S, et al. A cross-sectional study on the acceptability of self-collection for HPV testing among women in rural China. Sex Transm Infect. 2012;88(7):490-494. doi:10.1136/ sextrans-2012-050477

5. Zur Hausen H. Papillomavirus infections-a major cause of human cancers. Biochim Biophys Acta. 1996;1288(2):F55-F78. doi:10.1016/ 0304-419x(96)00020-0

6. Modis Y, Trus BL, Harrison SC. Atomic model of the papillomavirus capsid. EMBO J. 2002;21(18):4754-4762. doi:10.1093/emboj/cdf494

7. Buck CB, Cheng N, Thompson CD, et al. Arrangement of L2 within the papillomavirus capsid. $J$ Virol. 2008;82(11):5190-5197. doi:10.1128/JVI.02726-07

8. Yan H, Foo SS, Chen W, et al. Efficient inhibition of human papillomavirus infection by L2 minor capsid-derived lipopeptide. mBio. 2019;10:4. doi:10.1128/mBio.01834-19

9. Aydin I, Weber S, Snijder B, et al. Large scale RNAi reveals the requirement of nuclear envelope breakdown for nuclear import of human papillomaviruses. PLoS Pathog. 2014;10(5):e1004162. doi:10.1371/journal.ppat.1004162

10. Sapp M, Bienkowska-Haba M. Viral entry mechanisms: human papillomavirus and a long journey from extracellular matrix to the nucleus. Febs J. 2009;276(24):7206-7216. doi:10.1111/j.17424658.2009.07400.x
11. Florin L, Sapp M, Spoden GA. Host-cell factors involved in papillomavirus entry. Med Microbiol Immunol. 2012;201(4):437-448. doi:10.1007/s00430-012-0270-1

12. Wang JW, Roden RB. L2, the minor capsid protein of papillomavirus. Virology. 2013;445(1-2):175-186. doi:10.1016/j.virol.2013.04.017

13. Campos SK. Subcellular trafficking of the papillomavirus genome during initial infection: the remarkable abilities of minor capsid protein L2. Viruses. 2017;9:12. doi:10.3390/v9120370

14. DiGiuseppe S, Bienkowska-Haba M, Guion LG, Sapp M. Cruising the cellular highways: how human papillomavirus travels from the surface to the nucleus. Virus Res. 2017;231:1-9. doi:10.1016/j.virusres.2016.10.015

15. Han J, Zhang L, Guo H, et al. Glucose promotes cell proliferation, glucose uptake and invasion in endometrial cancer cells via AMPK/ mTOR/S6 and MAPK signaling. Gynecol Oncol. 2015;138 (3):668-675. doi:10.1016/j.ygyno.2015.06.036

16. Song K, Li M, Xu X, Xuan LI, Huang G, Liu Q. Resistance to chemotherapy is associated with altered glucose metabolism in acute myeloid leukemia. Oncol Lett. 2016;12(1):334-342. doi:10.3892/ol.2016.4600

17. Wang S, Li J, Xie J, et al. Programmed death ligand 1 promotes lymph node metastasis and glucose metabolism in cervical cancer by activating integrin beta4/SNAI1/SIRT3 signaling pathway. Oncogene. 2018;37(30):4164-4180. doi:10.1038/s41388-018-0252-x

18. van der Flier A, Sonnenberg A. Function and interactions of integrins. Cell Tissue Res. 2001;305(3):285-298. doi:10.1007/s004410100417

19. Neri P, Ren L, Azab AK, et al. Integrin beta7-mediated regulation of multiple myeloma cell adhesion, migration, and invasion. Blood. 2011;117(23):6202-6213. doi:10.1182/blood-2010-06-292243

20. Pals ST, Drillenburg P, Dragosics B, Lazarovits AI, Radaszkiewicz T. Expression of the mucosal homing receptor alpha 4 beta 7 in malignant lymphomatous polyposis of the intestine. Gastroenterology. 1994;107(5):1519-1523. doi:10.1016/0016-5085(94)90558-4

21. Michie SA, Streeter PR, Butcher EC, Rouse RV. L-selectin and alpha 4 beta 7 integrin homing receptor pathways mediate peripheral lymphocyte traffic to AKR mouse hyperplastic thymus. Am J Pathol. 1995;147(2):412-421.

22. Drillenburg P, van der Voort R, Koopman G, et al. Preferential expression of the mucosal homing receptor integrin alpha 4 beta 7 in gastrointestinal non-Hodgkin's lymphomas. Am J Pathol. 1997;150(3):919-927.

23. Rishi V, Bhattacharya $\mathrm{P}$, Chatterjee $\mathrm{R}$, et al. $\mathrm{CpG}$ methylation of half-CRE sequences creates C/EBPalpha binding sites that activate some tissue-specific genes. Proc Natl Acad Sci U S A. 2010;107 (47):20311-20316. doi:10.1073/pnas.1008688107

24. Kim MH, Fields J. Translationally regulated C/EBP beta isoform expression upregulates metastatic genes in hormone-independent prostate cancer cells. Prostate. 2008;68(12):1362-1371. doi:10.1002/pros.20801

25. Sun D, Wang C, Long S, et al. C/EBP-beta-activated microRNA-223 promotes tumour growth through targeting RASA1 in human colorectal cancer. Br J Cancer. 2015;112(9):1491-1500. doi:10.1038/bjc.2015.107

26. Wang Z, Liu Y, Lu L, et al. Fibrillin-1, induced by Aurora-A but inhibited by BRCA2, promotes ovarian cancer metastasis. Oncotarget. 2015;6(9):6670-6683. doi:10.18632/oncotarget.3118

27. Yang Y, Cao Y, Chen L, et al. Cryptotanshinone suppresses cell proliferation and glucose metabolism via STAT3/SIRT3 signaling pathway in ovarian cancer cells. Cancer Med. 2018;7(9):4610-4618. doi:10.1002/cam4.1691

28. Chiu CF, Peng JM, Hung SW, Liang CM, Liang SM. Recombinant viral capsid protein VP1 suppresses migration and invasion of human cervical cancer by modulating phosphorylated prohibitin in lipid rafts. Cancer Lett. 2012;320(2):205-214. doi:10.1016/j.canlet.2012.02.027

29. Chen TA, Wang JL, Hung SW, Chu CL, Cheng YC, Liang SM. Recombinant VP1, an Akt inhibitor, suppresses progression of hepatocellular carcinoma by inducing apoptosis and modulation of CCL2 production. PLoS One. 2011;6(8):e23317. doi:10.1371/journal.pone.0023317

30. Peng JM, Chen YH, Hung SW, et al. Recombinant viral protein promotes apoptosis and suppresses invasion of ovarian adenocarcinoma cells by targeting alpha5beta1 integrin to down-regulate Akt and MMP-2. Br J Pharmacol. 2012;165(2):479-493. doi:10.1111/ j.1476-5381.2011.01581.x 
31. Diamos AG, Larios D, Brown L, et al. Vaccine synergy with virus-like particle and immune complex platforms for delivery of human papillomavirus L2 antigen. Vaccine. 2019;37(1):137-144. doi:10.1016/j.vaccine.2018.11.021

32. Li M, Jiang X, Wang G, et al. ITGB4 is a novel prognostic factor in colon cancer. $J$ Cancer. 2019;10(21):5223-5233. doi:10.7150/ jca.29269

33. Moon JH, Rho YS, Lee $\mathrm{SH}$, et al. Role of integrin betal as a biomarker of stemness in head and neck squamous cell carcinoma Oral Oncol. 2019;96:34-41. doi:10.1016/j.oraloncology.2019.07. 001
34. Xia D, Chen B, Yang X. Correlation of integrin alpha 7 with clinicopathological characteristics and survival profiles, as well as its regulatory role in cell proliferation, apoptosis, and stemness in non-small-cell lung cancer. J Clin Lab Anal. 2019;33(8):e22973. doi:10.1002/jcla.v33.8

35. Li H, Yang F, Chai L, et al. CCAAT/enhancer binding protein beta-mediated MMP3 upregulation promotes esophageal squamous cell cancer invasion in vitro and is associated with metastasis in human patients. Genet Test Mol Biomarkers. 2019;23(5):304-309. doi:10.1089/gtmb.2018.0291

36. Zhao H, Sun J, Shao J, et al. Glucose transporter 1 promotes the malignant phenotype of non-small cell lung cancer through integrin beta1/Src/FAK signaling. J Cancer. 2019;10(20):4989-4997. doi:10.7150/jca.30772

\section{Publish your work in this journal}

OncoTargets and Therapy is an international, peer-reviewed, open access journal focusing on the pathological basis of all cancers, potential targets for therapy and treatment protocols employed to improve the management of cancer patients. The journal also focuses on the impact of management programs and new therapeutic agents and protocols on patient perspectives such as quality of life, adherence and satisfaction. The manuscript management system is completely online and includes a very quick and fair peer-review system, which is all easy to use. Visit http://www.dovepress.com/ testimonials.php to read real quotes from published authors. 